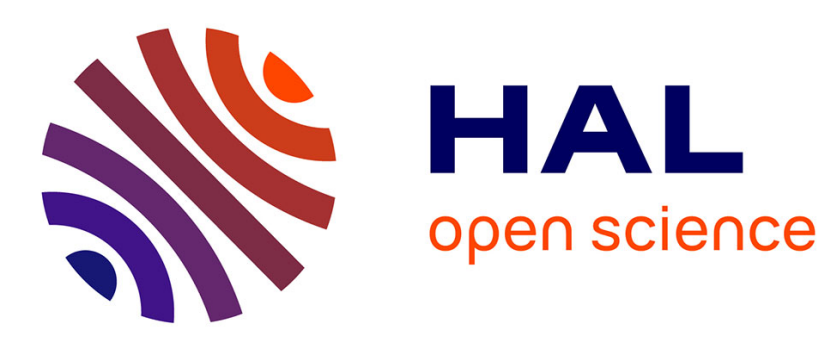

\title{
Brillouin fiber laser using As38Se62 suspended-core chalcogenide fiber
}

Kenny Hey Tow, Yohann Léguillon, Pascal Besnard, Laurent Brilland, Johann Troles, Périne Toupin, David Méchin, Denis Trégoat, Martine Doisy

\section{- To cite this version:}

Kenny Hey Tow, Yohann Léguillon, Pascal Besnard, Laurent Brilland, Johann Troles, et al.. Brillouin fiber laser using As38Se62 suspended-core chalcogenide fiber. SPIE Photonics Europe 2012, Apr 2012, Bruxelles, Belgium. pp.842611, 10.1117/12.921821 . hal-00696079

\section{HAL Id: hal-00696079 https://hal.science/hal-00696079}

Submitted on 10 May 2012

HAL is a multi-disciplinary open access archive for the deposit and dissemination of scientific research documents, whether they are published or not. The documents may come from teaching and research institutions in France or abroad, or from public or private research centers.
L'archive ouverte pluridisciplinaire HAL, est destinée au dépôt et à la diffusion de documents scientifiques de niveau recherche, publiés ou non, émanant des établissements d'enseignement et de recherche français ou étrangers, des laboratoires publics ou privés. 


\title{
Brillouin fiber laser using $\mathrm{As}_{38} \mathrm{Se}_{62}$ suspended-core chalcogenide fiber
}

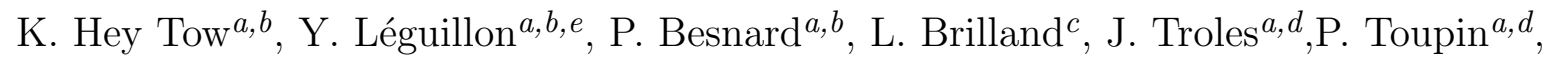 \\ D. Méchin ${ }^{c}$, D. Trégoat ${ }^{c}$, M. Doisy ${ }^{e}$ \\ ${ }^{a}$ UEB, Université Européenne de Bretagne, Université de Rennes I, France; \\ ${ }^{b}$ CNRS UMR 6082 FOTON, Enssat, 6 rue de Kerampont, BP 80518, 22305 Lannion, France; \\ ${ }^{c}$ PERFOS, 11 rue Louis de Broglie, 22300 Lannion, France; \\ ${ }^{d}$ Equipe Verres et Céramiques, CNRS, UMR 6226 Sciences Chimiques de Rennes, Campus de \\ Beaulieu, 35042 Rennes, France; \\ e Thales Underwater Systems, 525 route des Dolines, 06903 Sophia Antipolis Cedex, France.
}

\begin{abstract}
In this paper, an all-fiber Brillouin laser ring cavity using a 3-m-long suspended-core chalcogenide $\mathrm{As}_{38} \mathrm{Se}_{62}$ fiber is reported for the first time to our knowledge. For a nonresonant ring cavity with no servo-locking, a laser threshold power of $37 \mathrm{~mW}$ and an efficiency of $26 \%$ were obtained for a fiber having a core diameter of $5 \mu \mathrm{m}$. The linewidth of the Brillouin fiber laser and the pump laser were respectively measured to be below $4 \mathrm{kHz}$, the resolution of our autocorrelator, and $250 \mathrm{kHz}$, thus showing the linewidth-narrowing nature of the Brillouin laser. This result paves the way to compact Brillouin lasers with low threshold power and good spectral purity. A full experimental Brillouin characterization is also reported. We measured a Brillouin gain spectrum of 14.2 $\mathrm{MHz}$, a Brillouin gain coefficient of $5.6 \times 10^{-9} \mathrm{~m} / \mathrm{W}$ and a Brillouin frequency shift of $7.95 \mathrm{GHz}$ in our fiber.
\end{abstract}

Keywords: Stimulated Brillouin scattering; chalcogenide fiber; Brillouin gain coefficient; Brillouin gain spectrum; suspended-core fiber; Brillouin fiber laser.

\section{INTRODUCTION}

Although stimulated Brillouin scattering (SBS) in optical fiber is a penalizing nonlinear effect in optical communication systems, ${ }^{1}$ it is possible to make good use of SBS in other applications such as in optical amplification, ${ }^{2}$ optical sensing, ${ }^{3}$ slow light generation ${ }^{4}$ and Brillouin fiber lasers (BFLs). ${ }^{5}$ Silica-based optical fibers are often used for these applications. However, due to the relatively small Brillouin gain coefficient $g_{B}$ of $4 \times 10^{-11} \mathrm{~m} / \mathrm{W}$ in silica, ${ }^{6}$ optical fibers of several kilometers or pump power of several hundred milliwatts are required to reach Brillouin threshold. ${ }^{5}$

One approach to make low-power consuming and more compact devices based on SBS is to use a material with a higher Brillouin gain coefficient. SBS has been reported in bismuth ${ }^{7}$ tellurite, ${ }^{8} \mathrm{AsS}^{9}$ and $\mathrm{AsSe}^{9-11}$ chalcogenide bulk fibers with $g_{B}$ of $5 \times 10^{-11}, 1.7 \times 10^{-10}, 3.9 \times 10^{-9}$ and $6 \times 10^{-9} \mathrm{~m} / \mathrm{W}$ respectively. Another approach is to use fibers with large nonlinear efficiencies. Microstructured optical fibers (MOFs) offer the advantage of having reduced effective areas, thus ensuring a stronger light confinement of the electromagnetic field in the fiber core which increasing the nonlinearity of the bulk fiber. ${ }^{12}$

For our experiment, we have combined both alternatives by using a suspended-core microstructured fiber made of chalcogenide glass to make a BFL. These lasers have lately attracted much attention for many applications due to their extremely narrow linewidth. ${ }^{13}$ Chalcogenide MOFs are an attractive option to make BFLs. The high Brillouin gain coefficient in chalcogenide fibers, which is 134 times higher than in standard silica fibers, ${ }^{10}$ associated to the small effective area of a suspended-core structure, open the perspective of lower laser threshold as well as smaller laser cavity length. In 2010, self-phase modulation and 10-GHz four-wave mixing were demonstrated in a low-loss and ultra-highly nonlinear suspended-core AsSe chalcogenide fiber having a large

Further author information: (Send correspondence to Kenny Hey Tow)

Kenny Hey Tow: E-mail: heytow@enssat.fr, Telephone: +33 (0)2 96469155 
nonlinear coefficient of $31300 \mathrm{~W}^{-1} \mathrm{~m}^{-1} \cdot{ }^{14}$ Cascaded Raman wavelength shifting up to the fourth order ranging from 2092 to $2450 \mathrm{~nm}$ was also demonstrated in those fibers in 2011. ${ }^{15}$ Concerning Brillouin effects in MOFs, the $g_{B}$ in a MOF made of GeSbS chalcogenide fiber was measured to be $8 \times 10^{-10} \mathrm{~m} / \mathrm{W}^{16}$ and a $g_{B}$ of $5.91 \times 10^{-9}$ $\mathrm{m} / \mathrm{W}$ was predicted through theoretical simulation in a microstructured $\mathrm{As}_{2} \mathrm{Se}_{3}$ chalcogenide MOF having a $2-\mu \mathrm{m}$ hole-to-hole pitch and a $0.5-\mu \mathrm{m}$ hole diameter. ${ }^{17}$ But, to our knowledge, no BFL based on chalcogenide MOFs have yet been mentioned in the literature.

In this paper, we will report, for the first time to our knowledge, a Brillouin fiber laser made of chalcogenide microstructured optical fiber. Using a 3-m-long $A s_{38} S e_{62}$ fiber having a suspended-core structure with a 5- $\mu \mathrm{m}$ core diameter, a low threshold of $37 \mathrm{~mW}$ was obtained for nonresonant pumping with a noise reduction in terms of relative intensity noise and frequency noise as compared to the pump source. ${ }^{18}$ The article is organized as follows. First, the fabrication process of the fiber is described in the section 2. Section 3 is dedicated to the experimental characterization of stimulated Brillouin scattering (SBS) in these fibers. Finally, a BFL made of chalcogenide MOF is presented in section 4 and its noise performances are discussed in section 5 .

\section{SUSPENDED-CORE CHALCOGENIDE FIBERS}

The AsSe suspended-core fiber (figure 1) used in this paper is prepared with high purity glass. An $\mathrm{As}_{38} \mathrm{Se}_{62}$ glass rod is previously purified thanks to several synthesis steps using a small amount of oxygen and hydrogen getter. ${ }^{19}$ Then, the preform is prepared by using a casting method. ${ }^{20}$ The chalcogenide glass is heated around $500{ }^{\circ} \mathrm{C}$ and flowed into a silica mould which contains aligned silica capillaries. This method enables the realization of low loss fibers. During the drawing step, the hole sizes are adjusted by applying a positive pressure in the 3 holes of the preform. ${ }^{21}$ With a suspended-core structure, the fiber contains 3 holes around a solid core as shown in figure 1. The external diameter of the AsSe suspended-core fiber is $240 \mu \mathrm{m}$ and the core diameter $d$ is $5 \mu \mathrm{m}$. The mode effective area was estimated to be around $13 \mu \mathrm{m}^{2}$ and the fiber losses $\alpha$ were found to be $1 \mathrm{~dB} / \mathrm{m}$ at $1.55 \mu \mathrm{m}$.

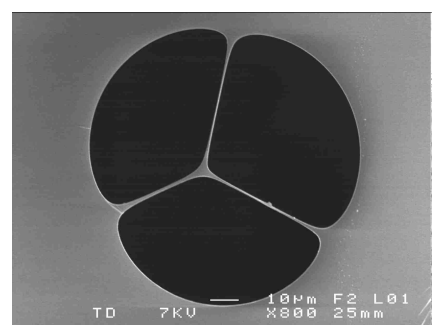

Figure 1. Transverse section of the AsSe suspended-core chalcogenide fiber

\section{BRILLOUIN GAIN COEFFICIENT AND BRILLOUIN GAIN SPECTRUM IN A SUSPENDED-CORE CHALCOGENIDE FIBER}

The experimental setup used to determine the Brillouin gain coefficient of the AsSe suspended-core chalcogenide fiber is detailed in figure 2. A commercial DFB fiber laser from NKT photonics, Koheras, having a spectral linewidth of around $1 \mathrm{kHz}$ and emitting at $1551.6 \mathrm{~nm}$, was used as pump laser (PL). This pump signal was amplified to $23 \mathrm{dBm}$ thanks to an erbium doped fiber amplifier (EDFA) and injected into the fiber via the port 2 of an optical circulator. A variable attenuator and a 90/10 coupler were also included in the experimental setup, which allowed variation and monitoring of the power injected in the chalcogenide fiber. The backscattered light from the fiber is collected at the port 3 for analysis. An optical spectrum analyzer (OSA) with a resolution of $10 \mathrm{MHz}$ was used to measure the intensity of the Stokes component for different pump powers.

Figure 3(a) shows the optical spectrum of the backscattered signal obtained on terminal 3 of the circulator for $20 \mathrm{dBm}$ of pump power. The peak observed at $1551.4 \mathrm{~nm}$ represents the Fresnel-reflected pump signal at the entry facet of the chalcogenide fiber caused by the large refractive index of 2.81 of the chalcogenide glass. 


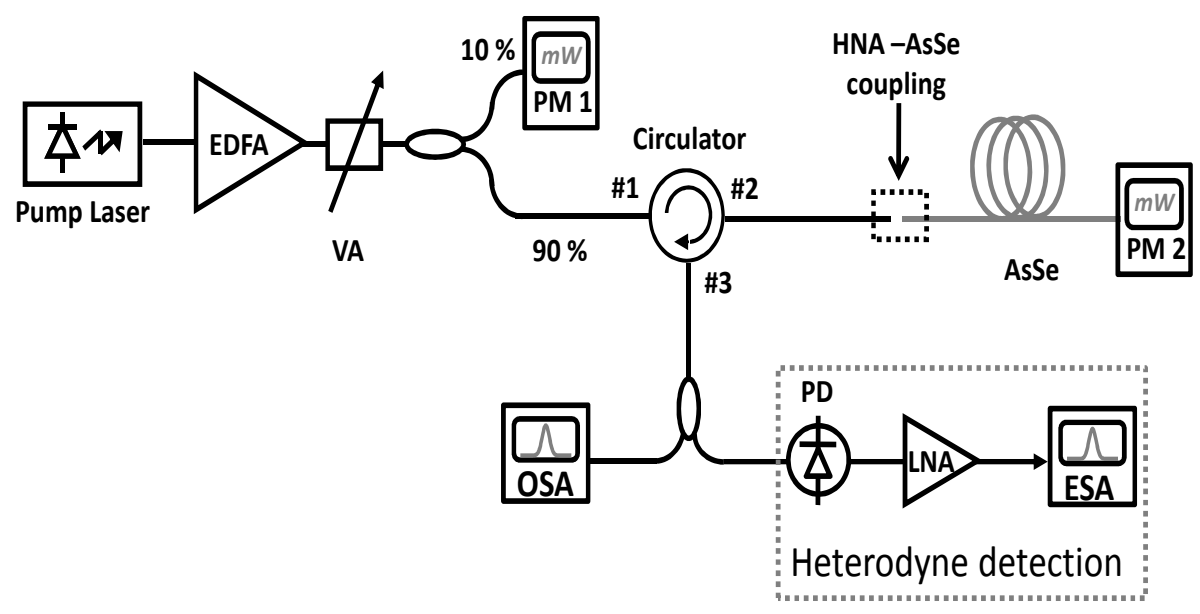

Figure 2. Experimental setup used for Brillouin characterization in AsSe suspended-core fiber

The second peak, redshifted by $0.0636 \mathrm{~nm}(-7.95 \mathrm{GHz})$ with respect to the pump signal, corresponds to a firstorder Stokes Brillouin component generated in the chalcogenide fiber. The third peak on Figure 3(a) is the back-reflected second-order Brillouin wave generated when the injected power exceeds $150 \mathrm{~mW}$.

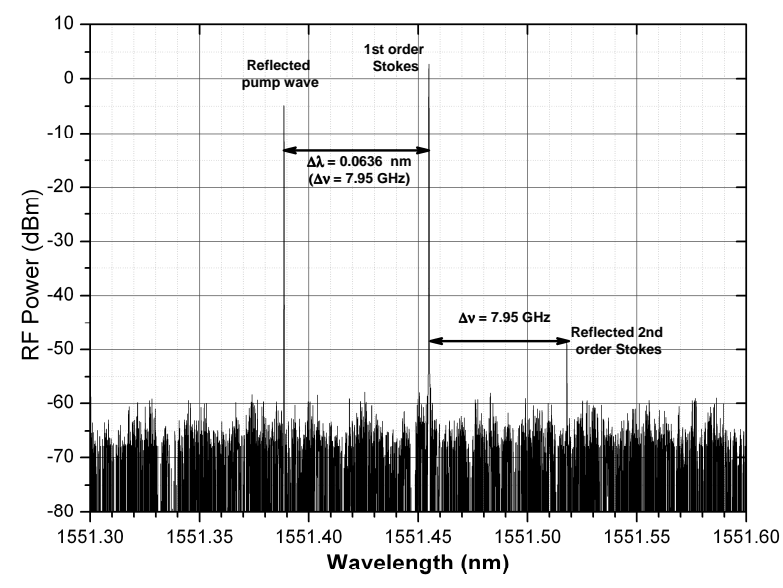

(a)

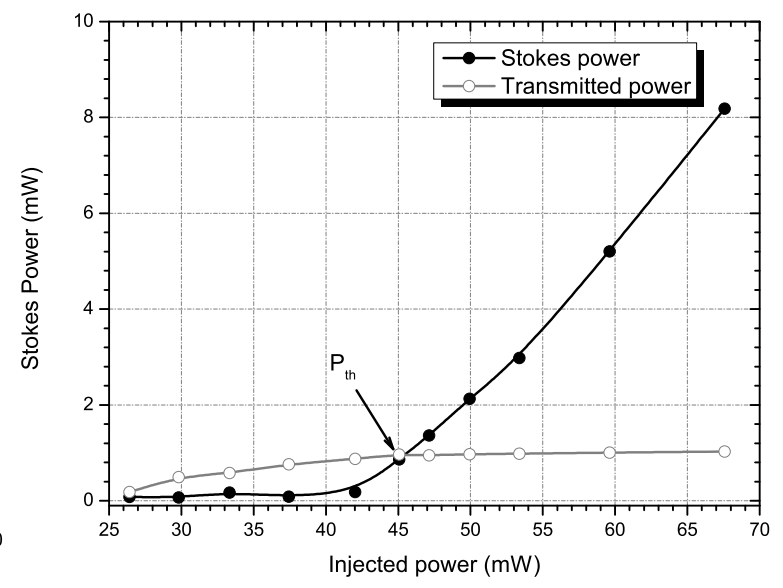

(b)

Figure 3. (a) Optical spectrum of the backscattered light from terminal 3 of the circulator (b) SBST measurement

In order to determine the SBS threshold power (SBST) and $g_{B}$, the backscattered power of the Brillouin component for different injected powers are plotted in figure 3(b). In fact, the SBST in an optical fiber is defined in various ways in the literature. One can arbitrarily define the SBS threshold power to be the pump power for which the backscattered Stokes power, $P_{\text {Stokes }}$ is equal to some fraction $\mu$ of the pump $P_{\text {pump }}$ such that $P_{\text {Stokes }}$ $=\mu \times P_{\text {pump }}$. Definitions with $\mu=0.01^{22-24}$ are often used in articles. For this paper, we have fixed $\mu=1^{6,16}$ to be able to compare our results with those given in the literature. Based on this latter definition, a SBST value $P_{t h}$ of $45 \mathrm{~mW}$ was measured for our fiber.

The Brillouin gain coefficient, $g_{B}$, can be determined from the SBS threshold power using the small-signal steady-state theory of stimulated Brillouin scattering ${ }^{6}$ :

$$
P_{t h} \approx 21 \frac{A_{e f f}}{L_{e f f} \cdot g_{B} \cdot K}
$$


where $A_{\text {eff }}$ is the effective area, $K$ a constant that depends on the polarization properties of the tested fiber ( $K=0.5$ for a standard single mode fiber and $K=1$ for a polarization maintaining fiber) and $L_{e f f}$ is the effective interaction length in our 3-m-long fiber $(L=3 \mathrm{~m})$ given by $L_{e f f}=1 / \alpha\left[\left(1-e^{-\alpha L}\right)\right]$. Our fiber has an $\alpha=1 \mathrm{~dB} / \mathrm{m}$, thus leading to an effective length of $2.16 \mathrm{~m}$. We have calculated a $g_{B}$ of $5.6 \times 10^{-9} \mathrm{~m} / \mathrm{W}$ for the suspended-core chalcogenide fiber. This value is compared to results published in the literature in table 1 . We can notice that the $g_{B}$ of a suspended-core AsSe chalcogenide fiber is two orders of magnitude higher than that of fused silica ${ }^{6}$ and slightly less than in a bulk chalcogenide fiber. This difference can be explained by the suspended-core structure and by the definition of the Brillouin threshold used in these articles.

Table 1. Brillouin gain coefficients measured in different chalcogenide fibers and in fused silica fiber at $1.55 \mu \mathrm{m}$

\begin{tabular}{|c|c|c|c|c|c|}
\hline Parameters & Silica $(\text { Agrawal })^{6}$ & AsS $(\text { Florea })^{9}$ & $\mathrm{As}_{2} \mathrm{Se}_{3}(\text { Abedin })^{10}$ & $\mathrm{As}_{2} \mathrm{Se}_{3}\left(\right.$ Florea $^{9}$ & $\mathrm{As}_{38} \mathrm{Se}_{62}($ FOTON $)$ \\
\hline $\mathrm{n}$ & 1,47 & 2.45 & 2,81 & 2,81 & 2,81 \\
$A_{\text {eff }}\left(\mu \mathrm{m}^{2}\right)$ & 67.8 & 13.9 & 39.4 & 63.1 & 13 \\
$\alpha(\mathrm{dB} / \mathrm{m})$ & 0.001 & 0.57 & 0.84 & 0.90 & 1.0 \\
$g_{B}(\mathrm{~W} / \mathrm{m})$ & $4.40 \mathrm{E}-11$ & $3.9 \mathrm{E}-9$ & $6.1 \mathrm{E}-9$ & $6.75 \mathrm{E}-9$ & $5.50 \mathrm{E}-9$ \\
\hline
\end{tabular}

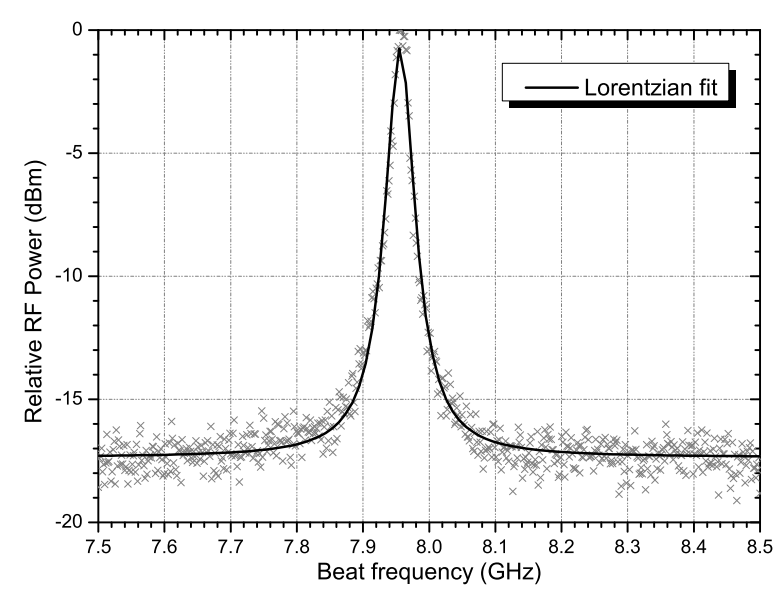

(a)

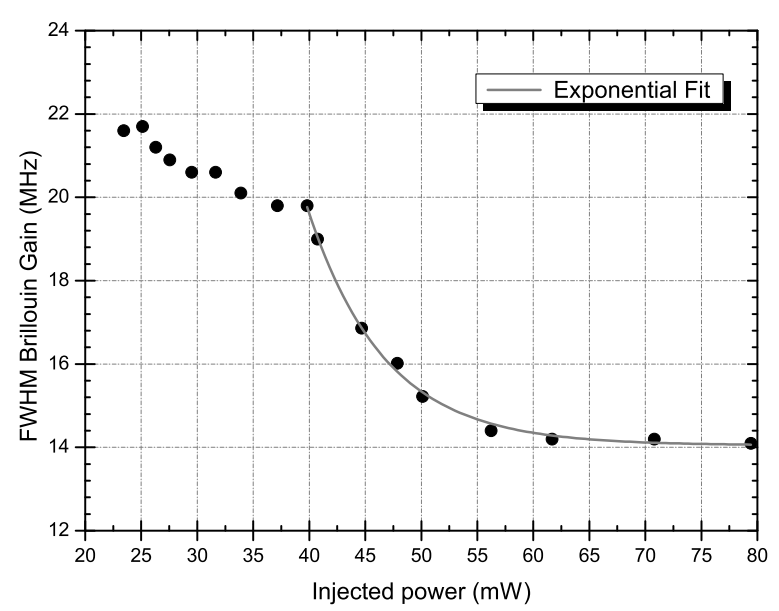

(b)

Figure 4. (a) Example of a Brillouin Gain Spectrum below threshold using a heterodyne detection. (b) Brillouin spectrum linewidth as a function of injected pump power.

A complement to the above characterization could include spectral characterization of the Brillouin Gain Spectrum (BGS) to quantify the Brillouin frequency shift, linewidth and gain shape. Several methods to measure the BGS are mentioned in the literature. ${ }^{25,26}$ A direct method to obtain the BGS in optical fiber is by using a heterodyne detection. ${ }^{27}$ This approach consists in interfering the pump wave with its generated Stokes wave, and subsequently converting the beat signal into the electrical domain, by means of a photodiode (PD) coupled to a low noise transimpedance amplifier (LNA), where it is resolved using an electric spectrum analyzer (ESA). The electrical signal spectrum reproduces the optical spectrum of the Brillouin signal with a higher resolution. In our case, the Fresnel-reflected pump signal at the entry facet of the chalcogenide fiber is used as a local oscillator for the heterodyne detection and is mixed with the backscattered Brillouin signal from the port 3 of the circulator. The measured BGS corresponding to an injected power of $25 \mathrm{~mW}$ is depicted on figure 4 (a). This experimental plot presents a Lorentzian spectral profile ${ }^{28}$ centered around $7.95 \mathrm{GHz}$, the Brillouin shift $\nu_{B}$ in our fiber. The curve can be fitted with a Lorentzian function from which a FWHM of $21.8 \mathrm{MHz}$ for the BGS is obtained. Increasing the injected power in the chalcogenide fiber leads to a narrowing of the SBS gain linewidth to a constant value, the linewidth of the spontaneous Brillouin scattering $\Delta \nu_{B}$ (as shown in figure 4(b)). This value, $14.2 \mathrm{MHz}$ for our fiber, is slightly larger than the $13.5 \mathrm{MHz}$ measured for a bulk fiber by Abedin et al, ${ }^{10}$ and can be explained by the presence of the air holes in the fiber. ${ }^{29,30}$ It is worth noting that since the pump 
laser linewidth $(\approx 1 \mathrm{kHz})$ is much smaller than the measured 3-dB BGS linewidth $(\approx 14 \mathrm{MHz})$, we can consider that the beating between the pump and the Stokes waves correspond to the 3-dB Brillouin gain linewidth. If not, a convolution correction must be taken into account. The $g_{B}$ of the suspended-core AsSe chalcogenide fiber can also be calculated from the 3 -dB BGS linewidth using the following equation ${ }^{31}$ :

$$
g_{B}=\frac{2 \pi n^{7} p_{12}^{2}}{c \rho_{0} \lambda_{p}^{2} \Delta \nu_{B} V_{a}}
$$

where $p_{12}$ is the longitudinal elasto-optic coefficient, $\lambda_{p}$ the pump wavelength, $c$ the vacuum velocity of light, $\rho_{0}$ the density of the material and $V_{a}$ the acoustic velocity. Taking $\Delta \nu_{B}=14.2 \mathrm{MHz}$, and also the published values of $n=2.81, \rho_{0}=4.64 \times 10^{3} \mathrm{~kg} / \mathrm{m}^{3}, V_{a}=2250 \mathrm{~m} / \mathrm{s}, p_{12}=0.266$, a $g_{B}$ of $5.75 \times 10^{-9} \mathrm{~m} / \mathrm{W}$ is calculated for our fiber. This value corresponds to the $g_{B}$ of $5.6 \times 10^{-9} \mathrm{~m} / \mathrm{W}$ measured using the SBST value.

\section{BRILLOUIN FIBER LASER MADE OF SUSPENDED-CORE CHALCOGENIDE FIBER}

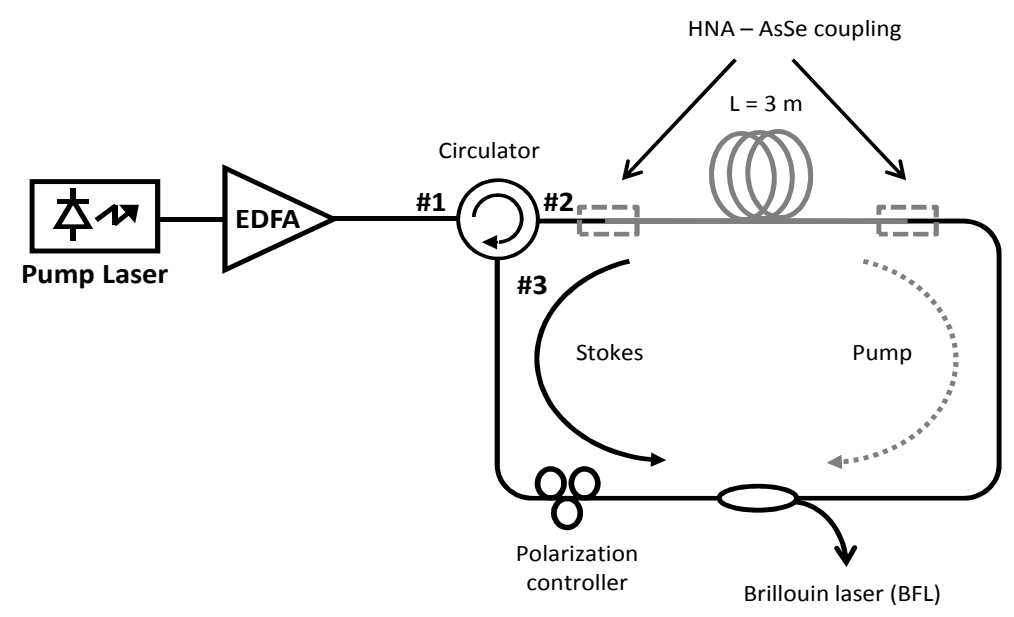

Figure 5. Experimental setup used for the Brillouin fiber ring laser

A compact Brillouin fiber ring laser was also made by using the 3-m-long fiber. The same experimental setup explained earlier was used. In this case, the ring cavity was obtained by connecting the terminal 3 of the circulator to the output facet of the chalcogenide fiber as shown in figure 5. The output of the BFL is extracted with a $10 \%$ fiber coupler. The remaining $90 \%$ is fed back into the cavity. This particular design of the BFL cavity with a circulator allows free propagation for the Stokes waves to perform multiple roundtrips, while the pump performs only a single roundtrip. The main advantage of this cavity over a conventional ring-resonator cavity $^{13,32}$ is that there are no resonant conditions for the pump, and thus, no need to servo-lock it with a feedback loop.

The Brillouin gain depends on the relative polarization between the pump and the Stokes wave since it originates from their coherent mixing. Our fiber being not polarization-maintained, a polarization controller was inserted into the cavity to ensure that the polarization of the pump is kept parallel to that of the Stokes wave thus yielding maximum Brillouin gain. ${ }^{33}$

The total cavity length of the ring laser is set to about 5 meters so that the free spectral range (FSR) of the ring cavity is less than the Brillouin gain bandwidth in the fiber. This results in only one single longitudinal mode Stokes wave oscillating in the ring cavity. The total round-trip losses, which include transmission losses in the chalcogenide fiber as well as the coupling losses, are estimated to be around $12 \mathrm{~dB}$.

Figure 6 shows the Brillouin laser output power as a function of the pump power. Pump power was measured thanks to a coupler inserted between the EDFA and the circulator and Brillouin laser output was measured at 


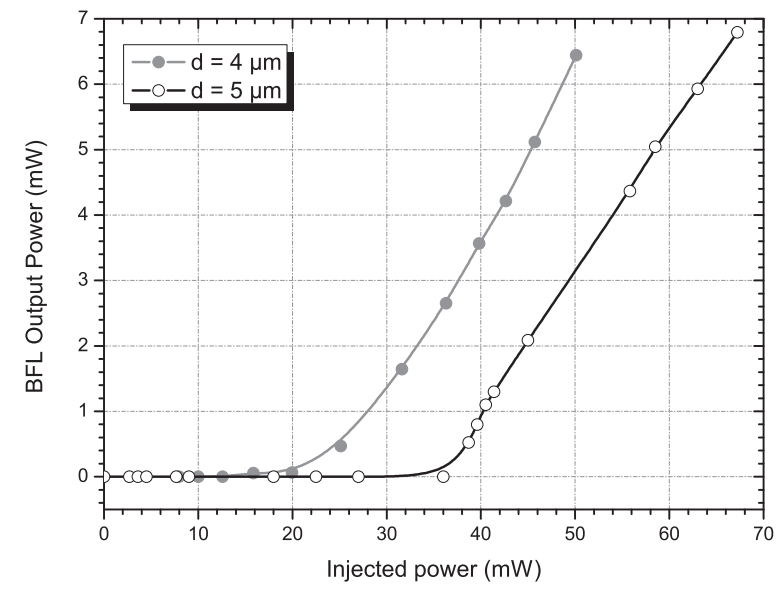

(a)

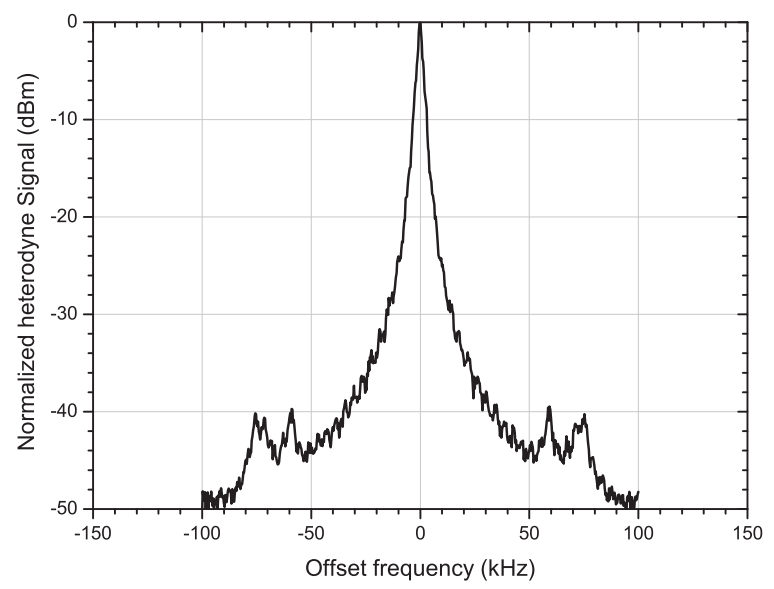

(b)

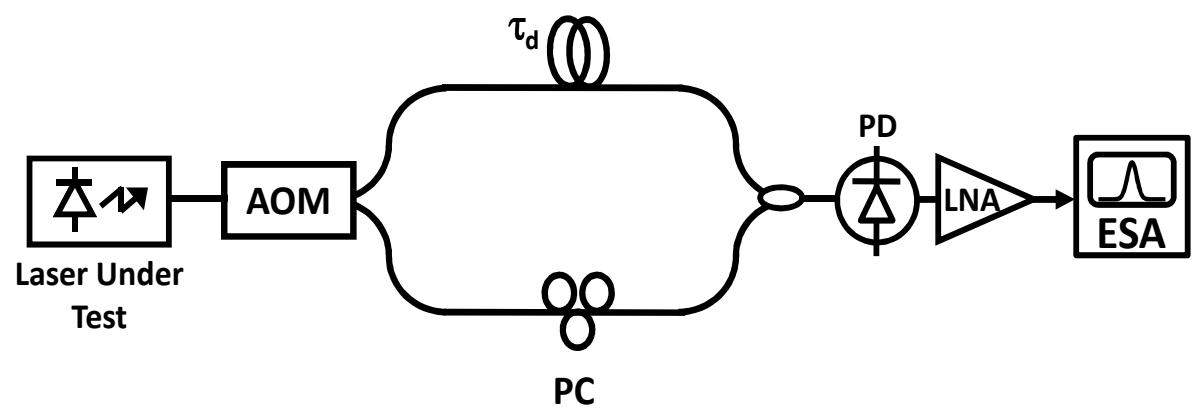

(c)

Figure 6. (a) BFL output power as a function of injected power. (b) Linewidth measurement of the lasers. (c) Experimental setup to measure the linewidth of a laser

the $10 \%$ port of the $90 / 10$ coupler. As shown in figure 6 , the output power is proportional to the pump power as expected. The BFL obtained with the AsSe fiber exhibits a low threshold of $37 \mathrm{~mW}$ for single pass pumping and converts the pump to the first-order Stokes wave with an efficiency of $26 \%$. The same experiment was performed using another suspended-core AsSe fiber having similar characteristics (length, losses) but having a smaller core diameter of $4 \mu \mathrm{m}$. This time a lower threshold of $22 \mathrm{~mW}$ was obtained.

A self-heterodyne detection technique, shown in figure 6(c), was set up using an unbalanced Mach-Zehnder interferometer to measure the linewidth of the Brillouin fiber laser. ${ }^{34}$ The output signal from the fiber laser is injected into an acousto-optic modulator (AOM) with a carrier frequency of $200 \mathrm{MHz}$ generated by a $\mathrm{RF}$ synthetiser. The first order, shifted at $200 \mathrm{MHz}$, and the delayed zero order are combined and detected by a photodiode associated to a RF electrical amplifier. The beat RF signal is measured using an ESA. A polarization controller (PC) has also been included in the setup to maximize the beat signal. A 50-km optical fiber delay line was used, which corresponds to a delay time of $240 \mu \mathrm{s}$ (resolution of $4 \mathrm{kHz}$ ). The self-heterodyne spectra of the AsSe BFL and the pump laser are illustrated on figure 6(b). Based on the oscillatory shape of the spectrum, ${ }^{35}$ thus suggesting that the length of the delay line used is too short to decorrelate the self-heterodyne beat signal. We can therefore conclude that the laser linewidth is less than $4 \mathrm{kHz}$.

\section{NOISE PERFORMANCES OF THE BFL}

The relative intensity noise (RIN) and the frequency noise of the BFL were also measured. Figure 7(a) shows the RIN of the BFL obtained using the method described by Poette et al. ${ }^{36}$ with a noise measurement limited to $10 \mathrm{MHz}$ due to the bandwidth of our low-noise transimpedance amplifier. The RIN of the pump source (PL), which includes the noise and the pump laser and that of the EDFA, was also included on the same plot for 
comparison. The RIN of the PL presents a classical behaviour: an excess noise for frequencies up to $10 \mathrm{kHz}$ brought by the EDFA followed by a peak due to the relaxation oscillation frequency (ROF) at $150 \mathrm{kHz}$ and by a decrease at higher frequencies. This ROF peak is transferred to the BFL with an overall noise reduction of about $5 \mathrm{~dB}$. However, an excess of intensity noise for the BFL is measured for frequencies above $3 \mathrm{MHz}$. It is also worth noting that the BFL is very sensitive to environmental noise as illustrated by the multiple noise peaks in the BFLs spectra for low frequencies $\left(10^{3} \mathrm{~Hz}-10^{4} \mathrm{~Hz}\right)$.

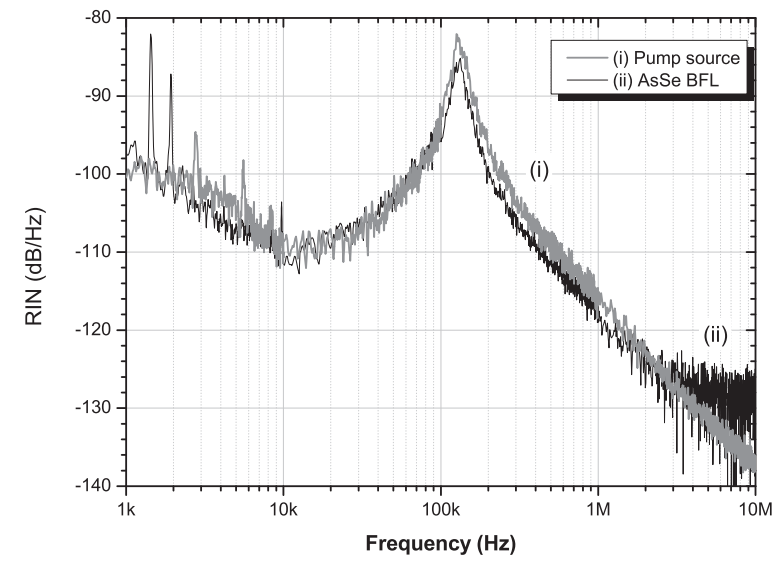

(a)

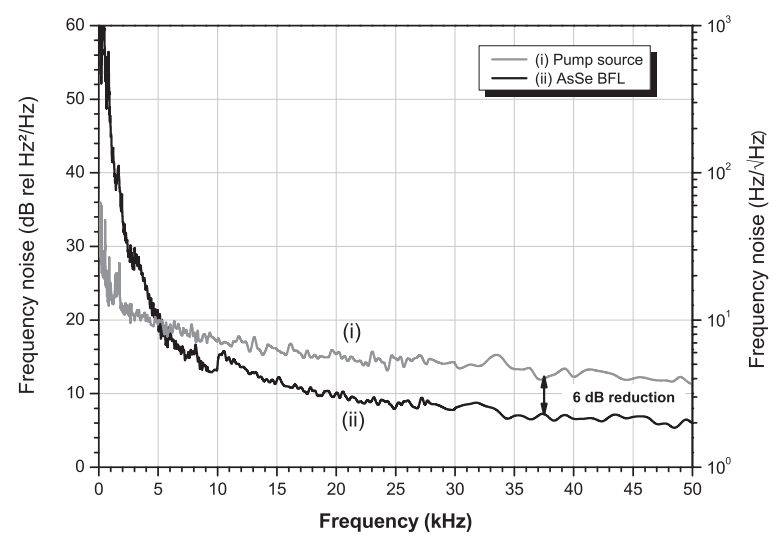

(b)

Figure 7. (a) Relative intensity noise spectra for (i) the pump laser source (ii) BFL (b) Frequency noise spectra for (i) the pump laser source (ii) BFL .

The frequency noise of the AsSe BFL (figure 7(b)) was also measured with the same setup illustrated in figure 6(c). This time, a delay length $L_{d}$ of $338 \mathrm{~m}$, which is less than the coherence length of the laser, was used. The system functions in coherent mode and the fluctuations of the frequency of the laser is measured by a signal source analyzer (R\&S FSUP8). The frequency noise spectra of the PL was also added on the same plot. As mentioned earlier, the BFL is very sensitive to environmental noise; this results in an important frequency noise contribution for frequencies below $5 \mathrm{kHz}$. This is, however, not the case for the Koheras PL since it is properly packaged making it insensible to thermal and acoustic variations. However, for frequencies above 5 $\mathrm{kHz}$, around $6 \mathrm{~dB}$ frequency noise reduction compared to the pump laser is observed as theoretically predicted $^{37}$ and experimentally demonstrated ${ }^{38}$ in silica BFLs.

\section{CONCLUSIONS AND PERSPECTIVES}

Stimulated Brillouin scattering in a suspended-core AsSe chalcogenide fiber, having a core diameter of $5 \mu \mathrm{m}$, was experimentally studied. A Brillouin shift of $7.95 \mathrm{GHz}$, a Brillouin gain coefficient of $5.6 \times 10^{-9} \mathrm{~m} / \mathrm{W}$ and a 3-dB Brillouin linewidth of $14.2 \mathrm{MHz}$ were measured. A compact, single-frequency Brillouin fiber laser was obtained using a 3-m long sample of our fiber. The linewidth of the BFL was measured to be below $4 \mathrm{kHz}$, the limit of resolution of our self-heterodyne measurement, thus demonstrating the very good spectral purity of the laser. The BFL had a threshold for as low as $37 \mathrm{~mW}$ with an efficiency of $26 \%$ for nonresonant pumping. This threshold was lowered to $22 \mathrm{~mW}$ for a BFL made of a fiber with a smaller core diameter of $4 \mu \mathrm{m}$. Moreover, this laser exhibits excellent noise properties; a relative intensity noise and frequency noise reduction as compared to the pump laser noise was measured for the BFL. BFLs operating at submilliwatt threshold power can even be achieved by the use of reported AsSe MOFs with smaller effective area and equivalent linear losses $\left(1.15 \mu \mathrm{m}^{2}\right.$ and $0.9 \mathrm{~dB} / \mathrm{m})^{15,39}$ or by resonant pumping of the fiber cavity, provided a Pound-Drever-Hall frequency-locking technique is used. ${ }^{40}$ 


\section{ACKNOWLEDGEMENT}

This work has been partially funded by the FEDER and French territorial and governmental organizations (Région Bretagne, LTA, CG22) through the "Sea Innovation \& Business Cluster (Pôle Mer)" in the framework of ATOS project and also through the PONANT project. 


\section{REFERENCES}

1. A. Chraplyvy, "Limitations on lightwave communications imposed by optical-fiber nonlinearities," Lightwave Technology, Journal of 8(10), pp. 1548-1557, 1990.

2. M. Ferreira, J. Rocha, and J. Pinto, "Analysis of the gain and noise characteristics of fibre brillouin amplifiers," Optical and quantum electronics 26(1), pp. 35-44, 1994.

3. M. Nikles, L. Thévenaz, and P. Robert, "Simple distributed fiber sensor based on Brillouin gain spectrum analysis," Optics letters 21(10), pp. 758-760, 1996.

4. K. Abedin, "Efficient Slow Light Generation Using Highly Nonlinear Non-Silica-Based Fibers," 2, pp. 309312, 2007.

5. K. Hill, B. Kawasaki, and D. Johnson, "CW Brillouin laser," Applied Physics Letters 28(10), pp. 608-609, 1976.

6. G. Agrawal, Nonlinear fiber optics, vol. 10, Academic press, 2008.

7. J. Lee, T. Tanemura, K. Kikuchi, T. Nagashima, T. Hasegawa, S. Ohara, and N. Sugimoto, "Experimental comparison of a kerr nonlinearity figure of merit including the stimulated brillouin scattering threshold for state-of-the-art nonlinear optical fibers," Optics letters 30(13), pp. 1698-1700, 2005.

8. G. Qin, A. Mori, and Y. Ohishi, "Brillouin lasing in a single-mode tellurite fiber," Optics letters 32(15), pp. 2179-2181, 2007.

9. C. Florea, M. Bashkansky, Z. Dutton, J. Sanghera, P. Pureza, and I. Aggarwal, "Stimulated Brillouin scattering in single-mode As2S3 and As2Se3 chalcogenide fibers," Optics Express 14(25), pp. 12063-12070, 2006.

10. K. Abedin, "Observation of strong stimulated Brillouin scattering in single-mode As2Se3 chalcogenide fiber," Optics Express 13(25), pp. 10266-10271, 2005.

11. K. Song, K. Abedin, K. Hotate, M. González Herráez, and L. Thévenaz, "Highly efficient Brillouin slow and fast light using As2Se3 chalcogenide fiber," Optics Express 14(13), pp. 5860-5865, 2006.

12. P. Russell, "Photonic crystal fibers," science 299(5605), p. 358, 2003.

13. S. Smith, F. Zarinetchi, and S. Ezekiel, "Narrow-linewidth stimulated brillouin fiber laser and applications," Optics letters 16(6), pp. 393-395, 1991.

14. D. Nguyen, S. Le, K. Lengle, D. Mechin, M. Thual, T. Chartier, Q. Coulombier, J. Troles, and L. Bramerie, "Demonstration of nonlinear effects in an ultra-highly nonlinear asse suspended-core chalcogenide fiber," IEEE Photonics Technology Letters 22(24), pp. 1844-1846, 2010.

15. M. Duhant, W. Renard, G. Canat, T. Nguyen, F. Smektala, J. Troles, Q. Coulombier, P. Toupin, L. Brilland, P. Bourdon, et al., "Fourth-order cascaded raman shift in asse chalcogenide suspended-core fiber pumped at $2 \mu \mathrm{m}, "$ Optics letters 36(15), pp. 2859-2861, 2011.

16. J. Fatome, C. Fortier, T. Nguyen, T. Chartier, F. Smektala, K. Messaad, B. Kibler, S. Pitois, G. Gadret, C. Finot, et al., "Linear and nonlinear characterizations of chalcogenide photonic crystal fibers," Journal of Lightwave Technology 27(11), pp. 1707-1715, 2009.

17. R. Cherif, M. Zghal, and L. Tartara, "Characterization of stimulated brillouin scattering in small core microstructured chalcogenide fiber," Optics Communications 285(3), pp. 341 - 346, 2012.

18. K. H. Tow, Y. Léguillon, P. Besnard, L. Brilland, J. Troles, P. Toupin, D. Méchin, D. Trégoat, and S. Molin, "Relative intensity noise and frequency noise of a compact brillouin laser made of as38se62 suspended-core chalcogenide fiber," Optics Letters (To be published), 2012.

19. J. Troles, V. Shiryaev, M. Churbanov, P. Houizot, L. Brilland, F. Desevedavy, F. Charpentier, T. Pain, G. Snopatin, and J. Adam, "Gese4 glass fibres with low optical losses in the mid-ir," Optical Materials 32(1), pp. 212-215, 2009.

20. Q. Coulombier, L. Brilland, P. Houizot, T. Chartier, T. NGuyen, F. Smektala, G. Renversez, A. Monteville, D. Méchin, and T. Pain, "Casting method for producing low-loss chalcogenide microstructured optical fibers," Optics Express 18(9), pp. 9107-9112, 2010.

21. J. Troles, Q. Coulombier, G. Canat, M. Duhant, W. Renard, P. Toupin, L. Calvez, G. Renversez, F. Smektala, and M. El Amraoui, "Low loss microstructured chalcogenide fibers for large non linear effects at 1995 nm," Optics Express 18(25), pp. 26647-26654, 2010. 
22. R. Smith, "Optical power handling capacity of low loss optical fibers as determined by stimulated raman and brillouin scattering," Applied Optics 11(11), pp. 2489-2494, 1972.

23. P. Bayvel and P. Radmore, "Solutions of the sbs equations in single mode optical fibres and implications for fibre transmission systems," Electronics letters 26(7), pp. 434-436, 1990.

24. J. Beugnot, T. Sylvestre, D. Alasia, H. Maillotte, V. Laude, A. Monteville, L. Provino, N. Traynor, S. Mafang, and L. Thévenaz, "Complete experimental characterization of stimulated brillouin scattering in photonic crystal fiber," Optics Express 15(23), pp. 15517-15522, 2007.

25. R. Tkach, A. Chraplyvy, and R. Derosier, "Spontaneous brillouin scattering for single-mode optical-fibre characterisation," Electronics Letters 22, pp. 1011 -1013, 111986.

26. M. Nikles, L. Thevenaz, and P. Robert, "Brillouin gain spectrum characterization in single-mode optical fibers," Lightwave Technology, Journal of 15(10), pp. 1842-1851, 1997.

27. A. Yeniay, J. Delavaux, and J. Toulouse, "Spontaneous and stimulated brillouin scattering gain spectra in optical fibers," Journal of lightwave technology 20(8), p. 1425, 2002.

28. D. Heiman, D. Hamilton, and R. Hellwarth, "Brillouin scattering measurements on optical glasses," Physical Review B 19(12), p. 6583, 1979.

29. P. Dainese, P. Russell, N. Joly, J. Knight, G. Wiederhecker, H. Fragnito, V. Laude, and A. Khelif, "Stimulated brillouin scattering from multi-ghz-guided acoustic phonons in nanostructured photonic crystal fibres," Nature Physics 2(6), pp. 388-392, 2006.

30. J. Spring and B. Ward, "Brillouin gain suppression in photonic crystal fibers with random acoustically microstructured cores," Optics Letters 35, pp. 31-33, Jan 2010.

31. D. Cotter, "Observation of stimulated brillouin scattering in low-loss silica fibre at 1.3 ã âं m," Electronics Letters 18(12), pp. 495-496, 1982.

32. L. Stokes, M. Chodorow, and H. Shaw, "All-fiber stimulated brillouin ring laser with submilliwatt pump threshold," Optics Letters 7(10), pp. 509-511, 1982.

33. R. Stolen, "Polarization effects in fiber raman and brillouin lasers," Quantum Electronics, IEEE Journal of 15(10), pp. 1157-1160, 1979.

34. L. Richter, H. Mandelberg, M. Kruger, and P. McGrath, "Linewidth determination from self-heterodyne measurements with subcoherence delay times," Quantum Electronics, IEEE Journal of 22(11), pp. 20702074, 2002.

35. C. Spiegelberg, J. Geng, Y. Hu, Y. Kaneda, S. Jiang, and N. Peyghambarian, "Low-noise narrow-linewidth fiber laser at $1550 \mathrm{~nm}, "$ Journal of Lightwave Technology 22(1), p. 57, 2004.

36. J. Poette, S. Blin, G. Brochu, L. Bramerie, R. Slavik, J.-C. Simon, S. LaRochelle, and P. Besnard, "Relative intensity noise of multiwavelength fibre laser," Electronics Letters 40, pp. 724 - 726, june 2004.

37. A. Debut, S. Randoux, and J. Zemmouri, "Linewidth narrowing in brillouin lasers: Theoretical analysis," Physical Review A 62(2), p. 023803, 2000.

38. J. Geng, S. Staines, Z. Wang, J. Zong, M. Blake, and S. Jiang, "Highly stable low-noise brillouin fiber laser with ultranarrow spectral linewidth," Photonics Technological Letters, IEEE 18(17), pp. 1813-1815, 2006.

39. S. D. Le, D. M. Nguyen, M. Thual, L. Bramerie, M. C. e Silva, K. Lenglé, M. Gay, T. Chartier, L. Brilland, D. Méchin, P. Toupin, and J. Troles, "Efficient four-wave mixing in an ultra-highly nonlinear suspended-core chalcogenide as38se62 fiber," Opt. Express 19, pp. B653-B660, Dec 2011.

40. E. Black, "An introduction to pound-drever-hall laser frequency stabilization," American Journal of Physics 69, p. 79, 2001. 